Article

\title{
Two New Bioactive $\alpha$-Pyrones from Hypericum japonicum
}

\author{
Linzhen $\mathrm{Hu}^{1}{ }^{1}$, Zhenzhen Wang ${ }^{2}$, Jinwen Zhang ${ }^{3}$, Yuanyuan $\mathrm{Lu}^{3}{ }^{3}$, Kaiping Wang ${ }^{2}$, Yongbo Xue ${ }^{2}$, \\ Yu Zhang ${ }^{1, *}$ and Yonghui Zhang ${ }^{2, *}$ \\ 1 Union Hospital Affiliated to Tongji Medical College, Huazhong University of Science and Technology, \\ Wuhan 430022, China; hlz198@126.com \\ 2 Hubei Key Laboratory of Natural Medicinal Chemistry and Resource Evaluation, School of Pharmacy, \\ Tongji Medical College, Huazhong University of Science and Technology, Wuhan 430030, China; \\ wzz75283@163.com (Z.W.); wkpzcq@163.com (K.W.); yongboxue@hust.edu.cn (Y.X.) \\ 3 Tongji Hospital Affiliated to Tongji Medical College, Huazhong University of Science and Technology, \\ Wuhan 430030, China; tjzhangjinwen@163.com (J.Z.); yuanyuanlu2016@163.com (Y.L.) \\ * Correspondence: whxhzy@163.com (YuZ.); zhangyh@mails.tjmu.edu.cn (Yo.Z.); Tel.: +86-27-83692762 (YuZ.); \\ +86-27-85726399 (Yo.Z.)
}

Academic Editor: Derek J. McPhee

Received: 18 March 2016; Accepted: 16 April 2016; Published: 19 April 2016

\begin{abstract}
Hypericum japonicum (Guttiferae), a type of annual or perennial herb, has been historically applied to cure infectious hepatitis, acute and chronic hepatitis, gastrointestinal disorder, and internal hemorrhage. In our successive studies on the genus Hypericum, two new $\alpha$-pyrones termed japopyrones A and B (1 and 2) were isolated from $\mathrm{H}$. japonicum. Their structures and absolute configurations were established by the comprehensive analyses of spectroscopic data, the application of the Single-crystal X-ray diffraction structural analysis, and the experimental electronic circular dichroism (ECD) spectra. Bioactivity screenings suggested that compound 2 possessed the potential inhibition efficacy on lytic replication of Kaposi's sarcoma associated herpesvirus (KSHV) with an $\mathrm{IC}_{50} 29.46 \mu \mathrm{M}$ and a selective index of higher than 6.79, respectively.
\end{abstract}

Keywords: Hypericum japonicum; pyrones; Kaposi's sarcoma associated herpes virus

\section{Introduction}

Hypericum japonicum (Guttiferae), a type of annual or perennial herb, is prosperously distributed from Liaoning and Shandong Provinces to the Southern Provinces of the Yangtze River in China [1]. As a type of Chinese traditional medicine, $H$. japonicum is mainly applied to cure infectious hepatitis, acute and chronic hepatitis, gastrointestinal disorder, and internal hemorrhage [2]. Furthermore, the extracts of Hypericum have been recorded as anti-depressant drugs in Europe and the Americas [1,3]. Currently, phytochemical investigations on this plant have led to the isolation of diverse chemical constituents such as xanthones [4], flavonoids [5], and phloroglucinols [6]. In our successive studies on the genus Hypericum [7-9], two new $\alpha$-pyrones termed japopyrones A and B (1 and 2) (Figure 1), were obtained from the air-dried aerial parts of $H$. japonicum. Previous reports showed that $\alpha$-pyrones served as bacterial signaling entities in the insect pathogen Photorhabdus [10], while some $\gamma$-pyrones exhibited coagulant activities in vitro [3]. Herein, the isolation, the structure elucidation, and the anti-Kaposi's sarcoma associated herpesvirus (KSHV) activities of compounds $\mathbf{1}$ and $\mathbf{2}$ are described. 


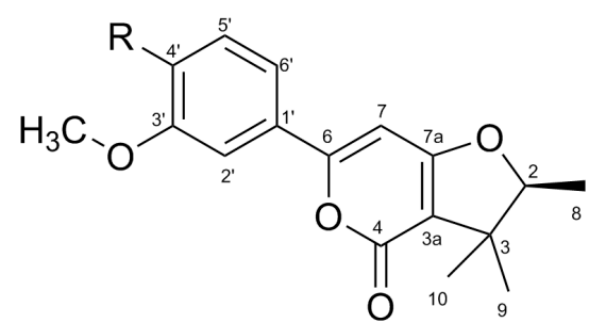

1: $\mathrm{R}=\mathrm{OH}$

2: $\mathrm{R}=\mathrm{OCH}_{3}$

Figure 1. Structures of compounds 1 and 2.

\section{Results}

The air-dried aerial parts of $H$. japonicum $(10 \mathrm{~kg})$ were soaked in $95 \% \mathrm{EtOH}$, which afforded a crude extract $(800 \mathrm{~g})$ under a vacuum evaporation. The crude extract was suspended in water and extracted sequentially with petroleum ether and $\mathrm{CHCl}_{3}$ for three times. The petroleum ether fraction (100 g) was chromatographed by silica gel column chromatography (silica gel CC), RP-18 Middle Pressure Liquid Chromatography (MPLC), and High Performance Liquid Chromatography (HPLC) to yield two new $\alpha$-pyrones ( $\mathbf{1}$ and $\mathbf{2}$ ) as shown in Figure 1, which were termed as japopyrones $\mathrm{A}$ and $\mathrm{B}$, respectively.

Japopyrone A (1), colorless crystal, $[\alpha]_{D}^{20}-55.7$ (c $\left.0.06, \mathrm{CH}_{3} \mathrm{OH}\right)$, has the molecular formula of $\mathrm{C}_{17} \mathrm{H}_{18} \mathrm{O}_{5}$, which was deduced by the HRESIMS positive peak at $m / z 325.1082\left([\mathrm{M}+\mathrm{Na}]^{+}\right.$, calcd as 325.1052) and ${ }^{13} \mathrm{C}-\mathrm{NMR}$ data. The analysis of IR spectrum implicated the characteristic functionalities with absorption bands at $3314 \mathrm{~cm}^{-1}$ (hydroxyl), $1697 \mathrm{~cm}^{-1}$ (conjugated ester carbonyl), and 1562 and $1512 \mathrm{~cm}^{-1}$ (phenyl). Compared the NMR data of 1 with the reported ones of saropyrone [11], the difference between compound $\mathbf{1}$ and saropyrone is that a methoxyl function at C- $3^{\prime}$ of $\mathbf{1}$ is replaced by a hydroxyl group in saropyrone. Coupled with the analysis of the HSQC spectrum, the ${ }^{1} \mathrm{H}$ - and ${ }^{13} \mathrm{C}-\mathrm{NMR}$ data were unambiguous assigned as shown in Table 1 . The ${ }^{1} \mathrm{H}-\mathrm{NMR}$ spectrum presented the signals of three methyls $\left(\delta_{\mathrm{H}} 1.34, \mathrm{~d}, J=6.6 \mathrm{~Hz} ; 1.30\right.$, s; and $\left.1.11, \mathrm{~s}\right)$, one methoxyl $\left(\delta_{\mathrm{H}} 3.83, \mathrm{~s}\right)$, three aromatic protons $\left(\delta_{\mathrm{H}} 7.35, \mathrm{~s} ; 6.87, \mathrm{~d}, J=8.0 \mathrm{~Hz}\right.$; and $\left.7.33, \mathrm{~d}, J=8.0 \mathrm{~Hz}\right)$, one proton $\left(\delta_{\mathrm{H}} 6.94, \mathrm{~s}\right)$, and one methine proton $\left(\delta_{\mathrm{H}} 4.61, \mathrm{q}, J=6.6 \mathrm{~Hz}\right)$. The ${ }^{13} \mathrm{C}-\mathrm{NMR}$ and DEPT 135 spectra showed 17 carbon signals which were eight quaternary carbon atoms (including one carbonyl, one aliphatic, and six aromatic/olefinic carbon atoms), five methines (including four aromatic/olefinic and one aliphatic carbon atom), three methyls, and one methoxyl $\left(\delta_{C} 55.8\right)$. The above analyses showed that compound 1 is a class of $\alpha$-pyrones.

Detailed analyses of the HMBC and ${ }^{1} \mathrm{H}_{-}{ }^{1} \mathrm{H}$ COSY spectra resulted in the structural connection of 1 (Figure 2). The HMBC spectrum exhibited the cross-peaks from $\mathrm{H}-2^{\prime}$ to $\mathrm{C}-1^{\prime}, \mathrm{C}-3^{\prime}, \mathrm{C}-4^{\prime}, \mathrm{C}-6^{\prime}$, and C-6, from $\mathrm{H}-5^{\prime}$ to $\mathrm{C}-1^{\prime}$ and $\mathrm{C}-3^{\prime}$, from $\mathrm{H}-6^{\prime}$ to $\mathrm{C}-6$, and from $\mathrm{C}^{\prime}-\mathrm{OCH}_{3}$ to $\mathrm{C}-3^{\prime}$, as well as a $\mathrm{H}-5^{\prime} / \mathrm{H}-6^{\prime}$ spin system of the ${ }^{1} \mathrm{H}-{ }^{1} \mathrm{H}$ COSY spectrum, which manifested the connection of a $1^{\prime}, 3^{\prime}, 4^{\prime}$-substituted benzene ring with an oxygen-bearing olefinic carbon viz. C- $6^{\prime}$. Furthermore, HMBC cross-peaks detected from H-7 to C-1', C-6, C-3a, and C-7a, implied the position of the olefinic double bond $\left(\Delta^{6,7}\right)$. In addition, HMBC correlations were observed from Me- 8 to C-2 and C-3, from Me-9 and Me-10 to C-3 and C-3a, and from H-2 to C-3, C-3a, and C-7a, together with an $\mathrm{H}-2 / \mathrm{H}-8$ spin system of the ${ }^{1} \mathrm{H}^{-1} \mathrm{H}$ COSY experiments, which indicated the location of Me-8, Me-9, and Me-10 at the furan ring and confirmed the fusion between furan and pyrone rings via $\mathrm{C}-7 \mathrm{a}$ and $\mathrm{C}-3 \mathrm{a}$. 
Table 1. ${ }^{1} \mathrm{H}-\mathrm{NMR}(400 \mathrm{MHz})$ and ${ }^{13} \mathrm{C}-\mathrm{NMR}(100 \mathrm{MHz})$ Spectral Data of Compounds 1 and 2 ( $\delta$ in ppm, $J$ in $\mathrm{Hz} ;{ }^{\mathrm{a}}$ in DMSO- $d_{6}$ and $^{\mathrm{b}}$ in methanol- $\left.d_{4}\right)$.

\begin{tabular}{|c|c|c|c|c|}
\hline \multirow{2}{*}{ NO. } & \multicolumn{2}{|l|}{$1^{a}$} & \multicolumn{2}{|l|}{$2^{b}$} \\
\hline & $\delta_{H}(p p m)$ & $\delta_{C}(p p m)$ & $\delta_{H}(p p m)$ & $\delta_{C}(\mathrm{ppm})$ \\
\hline 2 & $4.61 \mathrm{q}(J=6.6 \mathrm{~Hz})$ & 91.4 & $4.64 \mathrm{q}(J=6.6 \mathrm{~Hz})$ & 93.9 \\
\hline 3 & & 42.1 & & 43.9 \\
\hline 4 & & 159.7 & & 163.5 \\
\hline 6 & & 162.7 & & 164.8 \\
\hline 7 & $6.94 \mathrm{~s}$ & 91.6 & $6.77 \mathrm{~s}$ & 93.7 \\
\hline 8 & $1.34 \mathrm{~d}(J=6.6 \mathrm{~Hz})$ & 14.4 & $1.42 \mathrm{~d}(J=6.6 \mathrm{~Hz})$ & 14.9 \\
\hline 9 & $1.30 \mathrm{~s}$ & 25.1 & $1.40 \mathrm{~s}$ & 25.9 \\
\hline 10 & $1.11 \mathrm{~s}$ & 20.1 & $1.21 \mathrm{~s}$ & 20.6 \\
\hline $1^{\prime}$ & & 122.4 & & 125.5 \\
\hline $2^{\prime}$ & $7.35 \mathrm{~s}$ & 109.4 & $7.43 \mathrm{~d}(J=2.1 \mathrm{~Hz})$ & 110.2 \\
\hline $3^{\prime}$ & & 149.7 & & 150.9 \\
\hline $4^{\prime}$ & & 147.9 & & 153.5 \\
\hline $5^{\prime}$ & $6.87 \mathrm{~d}(J=8.0 \mathrm{~Hz})$ & 115.7 & $7.05 \mathrm{~d}(J=8.6 \mathrm{~Hz})$ & 112.9 \\
\hline $6^{\prime}$ & $7.33 \mathrm{~d}(J=8.0 \mathrm{~Hz})$ & 119.4 & $7.50 \mathrm{dd}(J=8.5,2.2 \mathrm{~Hz})$ & 120.8 \\
\hline $3 a$ & & 107.2 & & 109.6 \\
\hline $7 a$ & & 169.7 & & 172.8 \\
\hline $3^{\prime}-\mathrm{OCH}_{3}$ & $3.83 \mathrm{~s}$ & 55.8 & $3.90 \mathrm{~s}$ & 56.7 \\
\hline $4^{\prime}-\mathrm{OCH}_{3}$ & & & $3.89 \mathrm{~s}$ & 56.6 \\
\hline
\end{tabular}

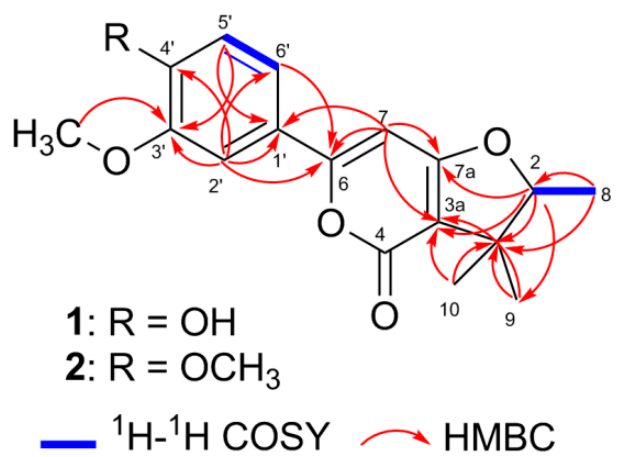

Figure 2. Key $\mathrm{HMBC}$ and ${ }^{1} \mathrm{H}^{-}{ }^{1} \mathrm{H}$ COSY correlations of compounds $\mathbf{1}$ and 2.

The absolute configuration of compound 1 was determined by a single-crystal X-ray diffraction structural analysis. Using the program SHELXL-2014/7, the structure solution and the refinement were achieved, which unequivocally established that the chiral characteristic of 1 was $2 S$. The X-ray ORTEP drawing of 1 was shown in Figure 3 (Flack's parameter 0.01(4), CCDC 1456415).

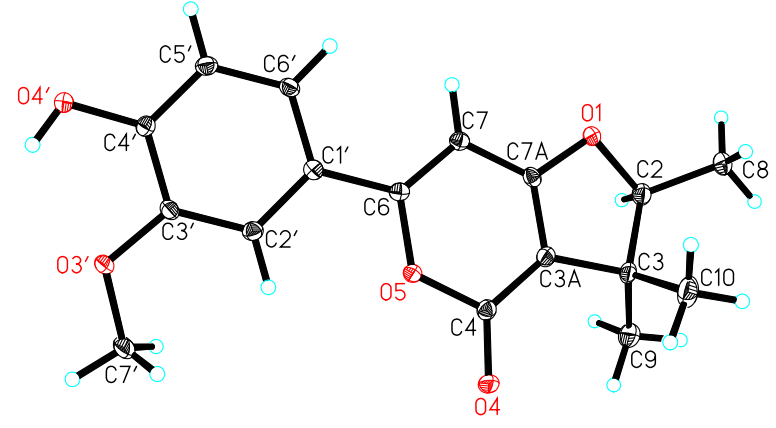

Figure 3. X- ray structure of 1 . 
Japopyrone B (2) was isolated as white amorphous powder with $[\alpha]_{D}^{20}-87.0\left(c 0.06, \mathrm{CH}_{3} \mathrm{OH}\right)$. Its molecular formula $\mathrm{C}_{18} \mathrm{H}_{20} \mathrm{O}_{5}$ was deduced by the positive pseudomolecular ion peak at $m / z 317.1382\left([\mathrm{M}+\mathrm{H}]^{+}\right.$, calcd as 317.1389) from a HRESIMS experiment and ${ }^{13} \mathrm{C}-\mathrm{NMR}$ data. A careful comparison of the 1D NMR data between 1 and 2 (Table 1) showed that the main differentiation between $\mathbf{1}$ and $\mathbf{2}$ were the presence of a hydroxyl group in 1 instead of a methoxyl group in $\mathbf{2}$ at C-4'. The key 2D correlations of compounds $\mathbf{2}$ were identical with 1 (Figure 2).

With the aid of experimental ECD spectra, the absolute sterochemistry of 2 was confirmed to be $2 S$, which was secured by the similar Cotton effects between 1 and 2 (Figure 4). Moreover, the levorotatory optical activities of compounds $\mathbf{1}$ and $\mathbf{2}$ also implied their coincident chiral characteristics.

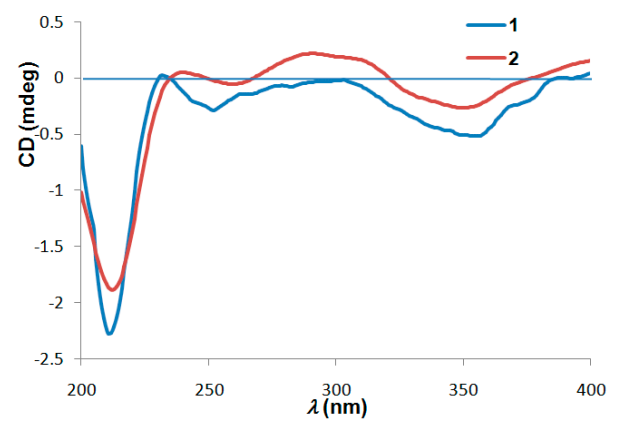

Figure 4. Experimental electronic circular dichroism (ECD) spectra of $\mathbf{1}$ and $\mathbf{2}$ (in $\left.\mathrm{CH}_{3} \mathrm{OH}\right)$.

Natural products have provided a rich resource for the discovery of new drugs, innovative therapeutic agents, and lead structures [12]. In our studious research towards the discovery for new lead compounds and useful bioactivities from Chinese traditional herbs, several bioactivity screenings such as cytotoxicity assays against five human cancer cell lines (HL-60, SMMC-7721, A-549, MCF-7, and SW480), inhibitory activities on NO production, and inhibitory activities on $\beta$-site amyloid precursor protein cleaving enzyme 1 (BACE1), were carried out for compounds 1 and $\mathbf{2}$. Unfortunately, both 1 and 2 exhibited inert activities with $\mathrm{IC}_{50}>40 \mu \mathrm{M}$ for cytotoxicity assays, $\mathrm{IC}_{50}>25 \mu \mathrm{M}$ for $\mathrm{NO}$ production inhibition assay, and $\mathrm{IC}_{50}>40 \mu \mathrm{M}$ for BACE1 inhibition assay, respectively.

Human gamma herpes viruses such as Kaposi's sarcoma-associated herpes virus (KSHV) is a type of pathogenic virus related to Kaposi's sarcoma, like epidemic KS, posttransplant KS, multicentric Castleman's disease, and primary effusion lymphoma [13,14]. Anti-infection towards lytic replication of KSHV plays a pivotal role as decreased a risk of KS, which were evidenced in cases of AIDS-associated epidemic KS patients [15,16]. In our exhaustive study to explore bioactivities of metabolites, an inhibition assay on lytic replication of KSHV was investigated for compounds 1 and 2 referring to the previous experiments [17]. The results (Table 2 and Figure 5) suggested that compound 2 had a potential efficacy with $\mathrm{IC}_{50} 29.46 \mu \mathrm{M}$ of inhibition towards 12-O-tetradecanoylphorbol-13-acetate (TPA)-induced lytic replication of $\mathrm{KSHV}$, with the value of $\mathrm{CC}_{50}$ higher than $200 \mu \mathrm{M}$, which means that the selective index is higher than 6.79. Meanwhile, compound 1 exhibited a moderate inhibition with $\mathrm{IC}_{50} 85.34 \mu \mathrm{M}$ and $\mathrm{CC}_{50}$ higher than $200 \mu \mathrm{M}$. The details of the dose-dependent manner were shown in Figure S1, Supplementary Materials. More elaborate procedures of anti-KSHV assay were also stated in Supplementary Materials.

Table 2. Anti-Kaposi's sarcoma associated herpesvirus (KSHV) activities of positive control cidofovir $(\mathrm{CDV}), \mathbf{1}$, and $2(\mu \mathrm{M})$.

\begin{tabular}{cccc}
\hline Compounds & $\mathrm{CC}_{\mathbf{5 0}}$ & $\mathrm{IC}_{\mathbf{5 0}}$ & Selective Index $\left(\mathrm{CC}_{\mathbf{5 0}} / \mathrm{IC}_{\mathbf{5 0}}\right)$ \\
\hline $\mathrm{CDV}$ & $>1$ & $<0.004$ & $>250$ \\
$\mathbf{1}$ & $>200$ & 85.34 & $>2.34$ \\
$\mathbf{2}$ & $>200$ & 29.46 & $>6.79$ \\
\hline
\end{tabular}



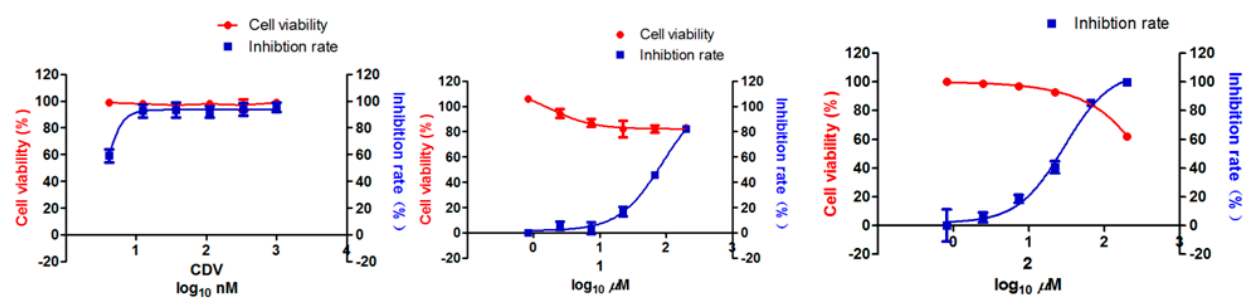

Figure 5. The effects of positive control cidofovir (CDV), $\mathbf{1}$ and $\mathbf{2}$ on human iSLK.219 cells viabilities and on lytic replication of KSHV infecting Vero cells were measured in vitro.

\section{Materials and Methods}

\subsection{General Experiments}

The following apparatuses were applied to acquire isolations and physical parameters of compounds 1 and 2. Silica gel H (160-200 mesh, Shanghai Xibao Biological Technology Co. Ltd, Shanghai, China) was used in column chromatography. ODS (50 $\mu \mathrm{m}$, Merck Co. Ltd., Darmstadt, Germany) and Sephadex LH-20 (GE Healthcare Bio-Sciences AB, Uppsala, Sweden) were taken as packing materials. High Performance Liquid Chromatography (HPLC) were carried out via a LC 3050 Analysis of HPLC system (CXTH, Beijing, China) assembled with an UV 3000 detector and a semi-preparative column $\left(5 \mu \mathrm{m}, 10 \times 250 \mathrm{~mm}, \mathrm{YMC}^{\circledR} \mathrm{XB}-\mathrm{C}_{18}\right)$. High-resolution electrospray ionization mass spectra (HRESIMS) were performed using a Thermo Fisher LC-LTQ-Orbitrap XL spectrometer (Thermo Fisher Scientific Inc., Waltham, MA, USA). UV and IR spectra data were recorded by a Varian Cary 50 (Varian Medical Systems, Salt Lake City, UT, USA) and Bruker Vertex 70 (Brucker Corporation, Karlsruhe, Germany) apparatuses. A Bruker AM-600/400 spectrometer (Brucker Corporation) was implemented to afford NMR spectra. The chemical shifts of ${ }^{1} \mathrm{H}$ - and ${ }^{13} \mathrm{C}-\mathrm{NMR}$ were referenced to the solvent peaks for DMSO- $d_{6}$ at $\delta_{\mathrm{H}} 2.50$ and $\delta_{\mathrm{C}} 39.5$ and methanol- $d_{4}$ at $\delta_{\mathrm{H}} 3.31$ and $\delta_{\mathrm{C}} 49.2$. Optical rotation values were recorded by a Perkin-Elmer 341 polarimeter (Perkin Elmer Inc., Waltham, MA, USA).

\subsection{Plant Material}

The air-dried aerial parts of H. japonicum were collected in November 2013 at Da-Bie Mountain area of Hubei Province, China and identified by Prof. Jianping Wang, School of Pharmacy, Tongji Medical College, Huazhong University of Science and Technology. A voucher sample (No. 2013-1111) has been deposited in the Herbarium of Hubei Key Laboratory of Natural Medicinal Chemistry and Resource Evaluation, School of Pharmacy, Tongji Medical College, Huazhong University of Science and Technology, Wuhan, China.

\subsection{Extraction and Isolation}

The air-dried aerial parts of H. japonicum $(10 \mathrm{~kg}$ ) were extracted four times with $95 \%$ aqueous EtOH at $40{ }^{\circ} \mathrm{C}$, which furnished extracts $(800 \mathrm{~g})$ under vacuum evaporation. The extracts were suspended in the water and sequentially extracted with petroleum ether and trichloromethane. TLC analyses were used to guide the next isolation project. The petroleum ether extracts (100 g) were subjected to silica gel CC via a gradient elution (petroleum ether-acetone, 100:1-1:1) to yield 10 fractions (Fr. 1-Fr. 10). Based on the TLC analysis, Fr. 8 was chosen and further repurified by normal-phase silica gel CC, reversed-phase silica gel CC, and Sephadex LH-20 to afford five subfractions (Fr. 8.1-Fr. 8.5). Finally, Fr. 8.3 was subjected to semi-preparative $\mathrm{HPLC}\left(\mathrm{CH}_{3} \mathrm{OH}-\mathrm{H}_{2} \mathrm{O} 35 \%\right)$ to obtain $1(4.2 \mathrm{mg})$ and 2 (4.5 mg).

Japopyrone A (1): colorless crystal; $[\alpha]_{D}^{20}-55.7$ (c 0.06, $\left.\mathrm{CH}_{3} \mathrm{OH}\right) ; \mathrm{UV}\left(\mathrm{CH}_{3} \mathrm{OH}\right) \lambda_{\max }(\log \varepsilon) 213(4.33), 235$ (3.10) 351 (3.21) nm; IR (KBr) $v_{\max } 3314,2966,2933,1697,1621,1582,1562,1512 \mathrm{~cm}^{-1} ; \operatorname{ECD} \lambda_{\max }(\Delta \varepsilon)$ 
$211(-0.79), 252(-0.10), 355(-0.18) \mathrm{nm} ;{ }^{1} \mathrm{H}-$ and ${ }^{13} \mathrm{C}-\mathrm{NMR}$ data, see Table 1 ; HRESIMS: $m / z$ z25.1082 $[\mathrm{M}+\mathrm{Na}]^{+}$(calcd for $\left.\mathrm{C}_{17} \mathrm{H}_{18} \mathrm{O}_{5} \mathrm{Na}, 325.1052\right)$.

Japopyrone B (2): white amorphous powder; $[\alpha]_{D}^{20}-87.0\left(c 0.06, \mathrm{CH}_{3} \mathrm{OH}\right) ; \mathrm{UV}\left(\mathrm{CH}_{3} \mathrm{OH}\right) \lambda_{\max }(\log \varepsilon)$ 214 (4.41), $344(4.29) \mathrm{nm}$; IR (KBr) $v_{\max } 2967,1725,1564,1515 \mathrm{~cm}^{-1}$; ECD $\lambda_{\max }(\Delta \varepsilon) 212(-4.28), 240$ $(+0.11), 291(+0.50), 350(-0.60) \mathrm{nm} ;{ }^{1} \mathrm{H}-$ and ${ }^{13} \mathrm{C}-\mathrm{NMR}$ data, see Table 1 ; HRESIMS: $m / z$ 317.1382 $[\mathrm{M}+\mathrm{H}]^{+}$(calcd for $\mathrm{C}_{18} \mathrm{H}_{21} \mathrm{O}_{5}, 317.1389$ ).

Single-crystal data for japopyrone A (1): $\mathrm{C}_{17} \mathrm{H}_{18} \mathrm{O}_{5}, \mathrm{M}=302.31, a=9.1711(2) \AA, b=11.4036(3) \AA$, $c=14.6711(4) \AA, \alpha=90^{\circ}, \beta=90^{\circ}, \gamma=90^{\circ}, V=1534.36(7) \AA^{3}, T=100(2) \mathrm{K}$, space group P212121, $Z=4$, $\mu(\mathrm{CuK} \alpha)=0.798 \mathrm{~mm}^{-1}, 16,146$ reflections measured, 2847 independent reflections $\left(R_{\text {int }}=0.0364\right)$. The final $R_{1}$ values were $0.0293(I>2 \sigma(I))$. The final $w R\left(F_{2}\right)$ values were $0.0780(I>2 \sigma(I))$. The final $R_{1}$ values were 0.0293 (all data). The final $w R\left(F_{2}\right)$ values were 0.0780 (all data). The goodness of fit on $F_{2}$ was 1.102. Flack parameter $=0.01(4)$.

The crystallographic data of japopyrone A (1): CCDC 1456415 contains the supplementary crystallographic data for this paper. These data can be obtained free of charge from the Cambridge Crystallographic Data Centre via www.ccdc.cam.ac.uk/data_request/cif.

\section{Conclusions}

Two new bioactive $\alpha$-pyrones, namely, japopyrones A (1) and B (2), were isolated from the aerial parts of Hypericum japonicum. The absolute configurations were determined by the analyses of the extensive spectra including HRESIMS, NMR, UV, and IR spectra, the application of the Single-crystal $X$-ray diffraction structural analysis, and the experimental electronic circular dichroism (ECD) spectra. Bioactivity screenings suggested that compound $\mathbf{2}$ had potential inhibition efficacy on lytic replication of KSHV with an $\mathrm{IC}_{50}$ of $29.46 \mu \mathrm{M}$ and the selective index being higher than 6.79 .

Supplementary Materials: The following are available online at: http://www.mdpi.com/1420-3049/21/4/515/s1, anti-KSHV assay, HRESIMS, NMR, UV, and IR spectra of compounds $\mathbf{1}$ and 2.

Acknowledgments: This work was financially supported by the Program for New Century Excellent Talents in University, the State Education Ministry of China (2008-0224), and the National Natural Science Foundation of China (Nos. 81573316, 31200258, 21502057, and 31500281).

Author Contributions: Yonghui Zhang and Yu Zhang conceived and designed the experiments; Linzhen $\mathrm{Hu}$ performed the experiments, analyzed the data, and wrote the manuscript; Zhenzhen Wang and Yuanyuan Lu carried out the biological assay; Jinwen Zhang, Kaiping Wang, and Yongbo Xue contributed reagents, materials, and analysis tools. All authors reviewed the manuscript.

Conflicts of Interest: The authors declare no conflict of interest.

\section{Abbreviations}

The following abbreviations are used in this manuscript:

$\begin{array}{ll}\text { H. japonicum } & \begin{array}{l}\text { Hypericum japonicum } \\ \text { electronic circular dichroism }\end{array} \\ \text { HRESIMS } & \text { High-resolution electrospray ionization mass spectra } \\ \text { CC } & \text { column chromatography } \\ \text { HPLC } & \text { High Performance Liquid Chromatography } \\ \text { BACE1 } & \beta \text {-site amyloid precursor protein cleaving enzyme 1 } \\ \text { KSHV } & \text { Kaposi's sarcoma associated herpes virus } \\ \text { TPA } & \text { 12-O-tetradecanoylphorbol-13-acetate } \\ \text { CDV } & \text { cidofovir } \\ \text { EtOH } & \text { ethanol }\end{array}$




\section{References}

1. Liu, L.S.; Liu, M.H.; He, J.Y. Hypericum japonicum Thunb. ex Murray: Phytochemistry, pharmacology, quality control and pharmacokinetics of an important herbal medicine. Molecules 2014, 19, 10733-10754. [CrossRef] [PubMed]

2. Wang, X.W.; Mao, Y.; Wang, N.L.; Yao, X.S. A new phloroglucinol diglycoside derivative from Hypericum japonicum Thunb. Molecules 2008, 13, 2796-2803. [CrossRef] [PubMed]

3. Wu, Q.L.; Wang, S.P.; Zhang, S.M.; Yang, J.S.; Xiao, P.G. Chromone glycosides and flavonoids from Hypericum japonicum. Phytochemistry 1998, 49, 1417-1420. [CrossRef]

4. Wu, Q.L.; Wang, S.P.; Du, L.J.; Yang, J.S. Xanthones from Hypericum japonicum and H. henryi. Phytochemistry 1998, 49, 1395-1402. [CrossRef]

5. Ishiguro, K.; Nagata, S.; Fukumoto, H.; Yamaki, M.; Isoi, K.; Oyama, Y. An isopentenylated flavonol from H. japonicum. Phytochemistry 1993, 32, 1583-1585. [CrossRef]

6. Hu, L.H.; Khoo, C.W.; Vittal, J.J.; Sim, K.Y. Phloroglucinol derivatives from Hypericum japonicum. Phytochemistry 2000, 53, 705-709. [CrossRef]

7. Zhu, H.; Chen, C.; Yang, J.; Li, X.N.; Liu, J.; Sun, B.; Huang, S.X.; Li, D.; Yao, G.; Luo, Z.; et al. Bioactive acylphloroglucinols with adamantyl skeleton from Hypericum sampsonii. Org. Lett. 2014, 16, 6322-6325. [CrossRef] [PubMed]

8. Zhu, H.; Chen, C.; Liu, J.; Sun, B.; Wei, G.; Li, Y.; Zhang, J.; Yao, G.; Luo, Z.; Xue, Y.; et al. Hyperascyrones A-H, polyprenylated spirocyclic acylphloroglucinol derivatives from Hypericum ascyron Linn. Phytochemistry 2015, 115, 222-230. [CrossRef] [PubMed]

9. Li, D.; Xue, Y.; Zhu, H.; Li, Y.; Sun, B.; Liu, J.; Yao, G.; Zhang, J.; Du, G.; Zhang, Y. Hyperattenins A-I, bioactive polyprenylated acylphloroglucinols from Hypericum attenuatum Choisy. RSC Adv. 2015, 5, 5277-5287. [CrossRef]

10. Brachmann, A.O.; Brameyer, S.; Kresovic, D.; Hitkova, I.; Kopp, Y.; Manske, C.; Schubert, K.; Bode, H.B.; Heermann, R. Pyrones as bacterial signaling molecules. Nat. Chem. Biol. 2013, 9, 573-578. [CrossRef] [PubMed]

11. Ishiguro, K.; Nagata, S.; Fukumoto, H.; Yamaki, M.; Isoi, K.; Yamagata, Y. A 2-Pyrone derivative from Hypericum japonicum. Phytochemistry 1994, 37, 283-284. [CrossRef]

12. Clardy, J.; Walsh, C. Lessons from natural molecules. Nature 2004, 432, 829-837. [CrossRef] [PubMed]

13. Chang, Y.; Cesarman, E.; Pessin, M.S.; Lee, F.; Culpepper, J.; Knowles, D.M.; Moore, P.S. Identification of herpesvirus-like DNA sequences in AIDS-associated Kaposi's Sarcoma. Science 1994, 266, 1865-1869. [CrossRef] [PubMed]

14. Cho, H.J.; Jeong, S.G.; Park, J.E.; Han, J.A.; Kang, H.R.; Lee, D.; Song, M.J. Antiviral activity of angelicin against gammaherpesviruses. Antivir. Res. 2013, 100, 75-83. [CrossRef] [PubMed]

15. Glesby, M.J.; Hoover, D.R.; Weng, S.; Graham, N.M.; Phair, J.P.; Detels, R.; Ho, M.; Saah, A.J. Use of antiherpes drugs and the risk of Kaposi's sarcoma: Data from the Multicenter AIDS Cohort Study. J. Infect. Dis. 1996, 173, 1477-1480. [CrossRef] [PubMed]

16. Martin, D.F.; Dunn, J.P.; Davis, J.L.; Duker, J.S.; Engstrom, R.E., Jr.; Friedberg, D.N.; Jaffe, G.J.; Kuppermann, B.D.; Polis, M.A.; Whitley, R.J.; et al. Use of the ganciclovir implant for the treatment of cytomegalovirus retinitis in the era of potent antiretroviral therapy: Recommendations of the International AIDS Society-USA panel. Am. J. Ophthalmol. 1999, 127, 329-339. [PubMed]

17. Chen, J.; Jiang, L.; Lan, K.; Chen, X. Celecoxib inhibits the lytic activation of Kaposi's Sarcoma-Associated Herpesvirus through down-regulation of RTA expression by inhibiting the activation of p38 MAPK. Viruses 2015, 7, 2268-2287. [CrossRef] [PubMed]

Sample Availability: Sample of the compound $\mathbf{1}$ is available from the authors.

(C) 2016 by the authors; licensee MDPI, Basel, Switzerland. This article is an open access article distributed under the terms and conditions of the Creative Commons Attribution (CC-BY) license (http:/ / creativecommons.org/licenses/by/4.0/). 